\title{
Dental caries experience and periodontal health status in a sample of autism children
}

\section{Abstract}

Background and Objective: Autism is a persistent neurodevelopmental condition. This study aimed to investigate carious and periodontal problems among a sample of children with autism in Erbil, Iraq.

Methods: A total of 44 autistic children aged 1-14 years (30 males and 14 females) attending Erbil, Iraq Autism Centers were enrolled in the study. The control group consisted of 44 non-autistic children chosen from different schools which represent different geographical locations in Erbil city in the period between September, $1^{\text {st }} 2014$ to January, $1^{\text {st }} 2015$ to have matched age, sex and socioeconomic status. Each patient received an assessment of caries prevalence. Other conditions assessed were oral hygiene and gingival health status. The $t$-test of significance was used to compare groups.

Results: Data analyzed for the present study comprised observations from a group of children (cases $=44$ ) diagnosed with autism matched with healthy children (controls $=44$ ). The autistic children had lower decayed, missing or filled teeth than unaffected children with nonsignificant differences. The mean decayed-missing-filled teeth in primary teeth (dmft) of the autistic group was $11.57 \pm 11.41$ while that of the controls was $15.36 \pm 12.81$. The mean Decayed-Missing-Filled teeth in permanent teeth (DMFT) of the autistic group was $2.36 \pm 3.86$ and $2.89 \pm 3.78$ in the controls. With advancing age, the value of decayed, missing and filled teeth increased. Almost all of the autistic children had fair oral hygiene $(1.291 \pm 0.89)$ and had gingivitis.

Conclusion: Autistic children displayed lower dmft, DMFT scores compared to control group, fair oral hygiene level, and had gingivitis than did the unaffected control children. Hence, non-autistic children need further consideration.

Keywords: Dental caries; Periodontal problems; Autistic spectrum disorders; Children.

\section{Introduction}

Autism spectrum disorder (ASD) is a persistent neurodevelopmental condition with early childhood onset. ${ }^{1}$ PDD is often used similarly with the term ASD and consists of five subtypes; (1) autism disorder (AD); (2) Asperger's Disorder; (3) Rett's disorder; (4) childhood disintegrative disorder (CDD); and (5) pervasive developmental disorder-not otherwise specified (PDD-NOS). The most popular and best studied form of ASD is $\mathrm{AD}^{2}{ }^{2}$ Autistic disorder is characterized by impairments in social interaction, communication, and restricted, repetitive patterns of behaviour, as well as complex sensory alterations. These signs all begin before a child is three years old..$^{3-4}$ Autism affects many parts of the brain; how this occurs is not understood ${ }^{5}$. It is a highly variable brain development disorder ${ }^{6}$ that first appears during infancy or childhood and generally follows a steady course without remission. ${ }^{7}$ Overt symptoms gradually begin after the age of six months, become established by age two or three years, ${ }^{8}$ and tend to continue through adulthood, although often in more muted form. ${ }^{5,9}$ Patients with autism spectrum disorder (ASD) are the individuals with

* Department of Peadodontics, Orthodontics and Preventive Dentistry, College of Dentistry, Hawler Medical University, Erbil, Iraq. 
special needs that demonstrate the greatest challenge for dentists, due to their complex and varied clinical manifestations. ${ }^{4}$ Management is of a multidisciplinary nature, the most effective strategies being based on educational pro-grams. ${ }^{10}$ The dental care of these patients poses great difficulties, and in most cases treatment is provided under general anesthe-sia. ${ }^{11}$ Most education programs for dentists and hygienists provide either extremely limited or no preparation for the care of individuals with disabilities. Essentially, half of dental hygiene school programs provide minimal didactic training and no clinical experience in the care of cases with special needs. $^{12}$ In 2004, the Commission on Dental Accreditation built a new standard that dental and dental hygiene programs were required to implement beginning January 1, 2006. The new standard states that "Graduates must be competent in assessing the treatment needs of patients with special needs." ${ }^{13}$ The prevalence estimated to be 1-2 per 1,000 for autism and close to 6 per 1,000 for Autism Spectrum Disorder, ${ }^{14}$ with about four times as many males as females. The number of people known to have autism has increased dramatically since the 1980s, partly due to the availability of services, age at diagnosis, changes in diagnostic practice, referral patterns, and public awareness, ${ }^{15}$ though unidentified environmental risk factors cannot be ruled out. ${ }^{16}$ There are little studies describing the oral health of individuals with autism. These studies reported no statistically significant differences in the prevalence of caries, gingivitis and degree of oral hygiene in comparison with non-autistic individuals. ${ }^{17-18}$ Nevertheless, many investigators have found the prevalence of caries and periodontal disease to be no different compared with non-autistic individuals. ${ }^{4}$ In some cases, the prevalence of caries in children with ASD may even be comparatively lower. ${ }^{11,19}$ Information on the patterns of development of the autistic disease in the population is important because it acts as a foundation for the planning of public oral health policies. Therefore, it was decided to conduct this study in order to find out the means of DMFT, dmft, Simplified Oral Hygiene Index $(\mathrm{OHI}-\mathrm{S})$ and gingival health status among the two study groups (autistic and non autistic) aged 1-14 years in Erbil, Iraq.

\section{Methods}

Study design: Case-control descriptive study.

Subjects' Selection: Forty-four autistic children (30 males and 14 females) attending autism centers of Erbil city, Iraq, were selected for the study. All the children had been previously diagnosed medically as autistic patients according to the center's medical records. Approval for examining the children was obtained from the parents and respective headmaster. The inclusion criteria included the diagnosis of autism, providing consent and age between 1 and 14 years. The exclusion criteria included suffering from other systemic diseases known to influence dental caries or the severity of periodontal diseases such as Down's syndrome and diabetes, dental prophylaxes in the last six months. Accordingly and following the inclusion and exclusion criteria of $\mathrm{JABER}^{5}$ in 2011,44 patients with autism were included in this study.

Comparison group selection: The healthy control group (44 subjects) was chosen from different schools which represent different geographical locations in Erbil city and was matched to the clinical group with regard to age, gender, general and dental care background and area of residence. All controls were medically fit and none was undergoing antibiotic or anti-inflammatory therapy or had undergone such therapy in the previous six months.

Examination: Examinations and oral health assessments were performed according to the basic method of the WHO for the year 1997. Each child accompanied 
by his/her teacher was brought to the examination room and subjects were seated in an ordinary adjustable chair and examined under fluorescent light with the use of disposable mouth mirror and sharp dental explorer ${ }^{20}$. "Tell-Show-Feel and Do" method was used with all the children. Teeth which manifest caries (DMFS/ dmfs) were diagnosed and scored according to the criteria suggested by (World Health Organization, 1987 cited by Shah et al., 2016). ${ }^{21}$ The oral hygiene status was estimated by using the Simplified Oral Hygiene Index (OHI-S) (Simplified Debris Index and Simplified Calculus Index). The OHI-S, introduced by Greene and Vermillion in 1964 and quoted by Peter (2004), ${ }^{22}$ each of these indices is based on numerical determinations representing the amount of debris or calculus on six pre-selected tooth surfaces, i.e., buccal surfaces of the selected upper first molars, lingual surfaces of the selected lower first molars, and the labial surfaces of the upper right and the lower left central incisors are inspected and scored. In the absence of either of these anterior teeth, the central incisors (21 or 41 respectively) on the opposite side of the midline are substituted. Simplified Debris Index (DI-S) $=$ (The buccal-scores) + (The lingual-scores) / (Total number of examined buccal and lingual surfaces).

Simplified Calculus Index $(\mathrm{Cl}-\mathrm{S})=$ (The buccal-scores) + (The lingual-scores) / (Total number of examined buccal and lingual surfaces).

The average individual or group debris and calculus scores were combined to obtain Simplified Oral Hygiene Index, as follows:

Simplified Oral Hygiene Index $(\mathrm{OHI}-\mathrm{S})=\mathrm{DI}$ $-\mathrm{S}+\mathrm{Cl}-\mathrm{S}$

The Simplified Oral Hygiene Index values range from $0-6$ and are as follows: Good (0-0.9); Fair (1.0-1.9); Poor (2.0 up to 6$).{ }^{23}$ Gingival index described by Loe and Silness (1963) was used for diagnosis and assessment of gingival health conditions, the severity of gingival inflammation was assessed according to Loe and Silness(1963) as Mild (0.1-1), Moderate (1.1-2), Severe (2.1-3), ${ }^{24}$ and the Ramfjord teeth was examined which is the following: $(16,21,24,36,41,44)$ for permanent and $(55,61,64,75,81,84)$ for deciduous, the missing tooth was not substituted. ${ }^{25}$

Data Analysis: The SPSS version 23 statistical package for Microsoft Windows ${ }^{\circledR}$ was used to analyze the data. The $t$-test was used to compare the means of quantitative variables between the two groups. The data were summarized and described using relative frequencies and percentages for categorical variables and means for the interval scaled variables (such as the DMFT/dmft score). Statistical significance was set at $P<0.05$.

\section{Results}

\section{Caries experience of deciduous teeth (dmft):}

Results found that the total mean value of (dmft) in the autistic group (11.57 \pm 11.41$)$ was lower than the control $(15.36 \pm 12.81)$ $(P=0.161)$, with no significant difference between them $(P>0.05)$ as shown in Table 1. Caries experience among females in autistic groups was higher than males, with no significant difference $(P>0.05)$ for autistic group only $(P=0.598)$. There was no significant difference between males and females in both groups within each age group $(P>0.05)$ except in age group (7-9) there is significant difference $(P=0.038)$, and highly significant in both groups in age group 10 and above $(P<0.001)$ in addition the $(\mathrm{dmft})$ value was increasing with advancing age in autistic group as demonstrated in Table 1. 
Table 1: Caries experience (dmft: mean and standard deviation) of deciduous teeth in the autistic and control groups by gender and age groups.

\begin{tabular}{|c|c|c|c|c|c|c|c|c|c|c|}
\hline \multirow{3}{*}{ Age Group } & \multirow{3}{*}{ Gender } & \multicolumn{4}{|c|}{ Autism Group } & \multicolumn{4}{|c|}{ Control Group } & \multirow{3}{*}{$P$ value ${ }^{* *}$} \\
\hline & & & & Dmft & & & & Dmft & & \\
\hline & & No & Mean & $\pm S D$ & $P$ value* & No & Mean & $\pm S D$ & $P$ value* & \\
\hline \multirow[t]{4}{*}{$1-3$} & Male & 1 & 0 & 0 & & 1 & 0 & 0 & & \\
\hline & & & & & $\mathrm{N} / \mathrm{A}$ & & & & N/A & $\mathrm{N} / \mathrm{A}$ \\
\hline & Female & 0 & 0 & 0 & & 0 & 0 & 0 & & \\
\hline & Total & 1 & 0 & 0 & & 1 & 0 & 0 & & \\
\hline \multirow[t]{4}{*}{$4-6$} & Male & 9 & 12.44 & 14 & & 9 & 13.9 & 11.36 & & \\
\hline & & & & & 0.244 & & & & 0.101 & 0.756 \\
\hline & Female & 7 & 5.43 & 7 & & 7 & 6.29 & 2.06 & & \\
\hline & Total & 16 & 9.38 & 11.7 & & 16 & 10.6 & 9.26 & & \\
\hline \multirow[t]{4}{*}{ 7-9 } & Male & 13 & 13.92 & 6.64 & & 13 & 26.2 & 12.66 & & \\
\hline & & & & & 0.167 & & & & 0.29 & $0.038^{* * *}$ \\
\hline & Female & 5 & 19.4 & 8.73 & & 5 & 19.4 & 9.21 & & \\
\hline & Total & 18 & 15.47 & 7.45 & & 18 & 23.2 & 12.57 & & \\
\hline \multirow[t]{3}{*}{10 \& Above } & Male & 5 & 9.11 & 6 & & 6 & 3.17 & 5.19 & $* * *$ & \\
\hline & Female & 23 & 32.53 & 3 & $<0.001$ & 3 & 23.3 & 8.62 & $<0.001$ & 0.228 \\
\hline & Total & 9 & 16.05 & 9 & & 9 & 9.89 & 11.71 & & \\
\hline \multirow[t]{4}{*}{ Total } & Male & 30 & 10.93 & 10.3 & & 29 & 16.7 & 14.29 & & \\
\hline & & & & & 0.598 & & & & 0.341 & 0.161 \\
\hline & Female & 14 & 12.93 & 13.8 & & 15 & 12.7 & 9.17 & & \\
\hline & Total & 44 & 11.57 & 11.4 & & 44 & 15.4 & 12.81 & & \\
\hline
\end{tabular}

${ }^{*}$ This $P$ value is to compare males with females.

** This $P$ value compares the total values of the two groups.

*** Significant $(P<0.05)$.

****Highly significant $(P<0.001)$. 
Caries experience of permanent teeth (DMFT):

The results found that the total mean of (DMFT) in autistic group (2.36 \pm 3.86$)$ was less than that in the control $(2.89 \pm 3.78)$ $(P=0.524)$, with no significant differences $(P>0.05)$. The caries experience (DMFT) among males was higher than females in both autistic and control groups but with a non-significant difference $(P>0.05)$ as seen in Table 2. The statistical differences between males and females in all age group in relation to (DMFT) were not significant $(P>0.05)$, and the means of (DMFT) was increasing with advancing age in both groups.

Table 2: Caries experience (DMFT: means and standard deviation) of permanent teeth in the autistic and control groups by gender and age groups.

\begin{tabular}{|c|c|c|c|c|c|c|c|c|c|c|}
\hline \multirow{3}{*}{$\begin{array}{l}\text { Age } \\
\text { Group }\end{array}$} & \multirow{3}{*}{ Gender } & \multicolumn{5}{|c|}{ Autism Group } & \multicolumn{3}{|c|}{ Control Group } & \multirow{3}{*}{$P$ value ** } \\
\hline & & & & MFT & & & & MFT & & \\
\hline & & No & Mean & $\pm S D$ & $P$ value* & No & Mean & $\pm S D$ & $P$ value ${ }^{*}$ & \\
\hline \multirow[t]{3}{*}{$4-6$} & Male & 9 & 0 & 0 & & 9 & 0.44 & 1.01 & & \\
\hline & Female & 7 & 0.57 & 1.51 & $\mathrm{~N} / \mathrm{A}$ & 7 & 0 & 0 & $\mathrm{~N} / \mathrm{A}$ & $\mathrm{N} / \mathrm{A}$ \\
\hline & Total & 16 & 0.25 & 1 & & 16 & 0.25 & 0.77 & & \\
\hline \multirow[t]{3}{*}{$7-9$} & Male & 13 & 2.31 & 2.75 & & 13 & 3.23 & 2.86 & & \\
\hline & Female & 5 & 1.4 & 1.52 & 0.498 & 5 & 3.4 & 2.7 & 0.909 & 0.177 \\
\hline & Total & 18 & 2.06 & 2.46 & & 18 & 3.28 & 2.74 & & \\
\hline \multirow{3}{*}{$\begin{array}{l}10 \& \\
\text { Above }\end{array}$} & Male & 7 & 6.29 & 5.41 & & 7 & 7 & 5.4 & & \\
\hline & Female & 2 & 9.5 & 7.78 & 0.5 & 2 & 8.67 & 2.08 & 0.621 & 0.8177 \\
\hline & Total & 9 & 7 & 5.61 & & 9 & 7.56 & 4.48 & & \\
\hline \multirow[t]{3}{*}{ Total } & Male & 29 & 2.47 & 3.85 & & 29 & 3.03 & 3.86 & & \\
\hline & Female & 14 & 2.14 & 4.04 & 0.797 & 14 & 2.87 & 3.76 & 0.897 & 0.524 \\
\hline & Total & 43 & 2.36 & 3.86 & & 43 & 2.89 & 3.78 & & \\
\hline
\end{tabular}

*This $P$ value is to compare males with females.

**This $P$ value compares the total values of the two groups. 
Simplified oral hygiene index (OHI-S): values of OHI-S than females with The results found that the mean of a significant difference $(P=0.042)$ as shown $\mathrm{OHI}-\mathrm{S}$ in the control group compared to the autistic group (1.69 \pm 0.806$)$ and $(1.291 \pm 0.89)$ respectively and both groups showed fair oral hygiene. The males in both groups showed higher mean in Table 3 . In age group 4-6 years old, there was a highly significant difference $(P<0.001)$, while in autistic group significant differences $(P=0.044)$.

Table 3: Simplified oral hygiene index (mean and standard deviation) of the autistic and control groups by gender and age groups.

\begin{tabular}{|c|c|c|c|c|c|c|c|c|c|c|}
\hline \multirow[t]{2}{*}{$\begin{array}{l}\text { Age } \\
\text { Group }\end{array}$} & \multirow[t]{2}{*}{ Gender } & \multicolumn{4}{|c|}{ OHI-S } & \multicolumn{4}{|c|}{ OHI-S } & \multirow[t]{2}{*}{$P$ value ${ }^{* *}$} \\
\hline & & No & Mean & $\pm S D$ & $P$ value* & No & Mean & $\pm S D$ & $P$ value* & \\
\hline \multirow[t]{3}{*}{$1-3$} & Male & 1 & 0.5 & 0 & \multirow{3}{*}{ N/A } & 1 & 1 & 0 & \multirow{3}{*}{$\mathrm{N} / \mathrm{A}$} & \multirow{3}{*}{$\mathrm{N} / \mathrm{A}$} \\
\hline & Female & 0 & 0 & 0 & & 0 & 0 & 0 & & \\
\hline & Total & 1 & 0 & 0 & & 1 & 0 & 0 & & \\
\hline \multirow[t]{3}{*}{$4-6$} & Male & 9 & 0.797 & 0.3 & \multirow{3}{*}{$0.044^{* * *}$} & 9 & 1.18 & 0.244 & \multirow{3}{*}{0.949} & \multirow{3}{*}{$<0.001^{* * * *}$} \\
\hline & Female & 7 & 0.466 & 0.31 & & 7 & 1.19 & 0.241 & & \\
\hline & Total & 16 & 0.652 & 0.34 & & 16 & 1.18 & 0.234 & & \\
\hline \multirow[t]{3}{*}{ 7-9 } & Male & 13 & 1.589 & 0.75 & \multirow{3}{*}{0.645} & 13 & 1.64 & 0.693 & \multirow{3}{*}{0.72} & \multirow{3}{*}{0.896} \\
\hline & Female & 5 & 1.798 & 1.09 & & 5 & 1.78 & 0.779 & & \\
\hline & Total & 18 & 1.647 & 0.83 & & 18 & 1.68 & 0.697 & & \\
\hline \multirow{3}{*}{$\begin{array}{l}10 \& \\
\text { Above }\end{array}$} & Male & 7 & 1.671 & 1.15 & \multirow{3}{*}{0.888} & 7 & 2.9 & 0.927 & \multirow{3}{*}{0.398} & \multirow{3}{*}{0.063} \\
\hline & Female & 2 & 2.255 & 0.77 & & 2 & 2.27 & 0.252 & & \\
\hline & Total & 9 & 1.801 & 1.07 & & 9 & 2.69 & 0.808 & & \\
\hline \multirow[t]{3}{*}{ Total } & Male & 30 & 1.334 & 0.84 & \multirow{3}{*}{0.552} & 30 & 1.74 & 0.889 & \multirow{3}{*}{0.603} & \multirow{3}{*}{$0.042^{\star \star *}$} \\
\hline & Female & 14 & 1.197 & 1.03 & & 14 & 1.6 & 0.632 & & \\
\hline & Total & 44 & 1.291 & 0.89 & & 44 & 1.69 & 0.806 & & \\
\hline
\end{tabular}

*This $P$ value is to compare males with females.

** This $P$ value compares the total values of the two groups.

***Significant $(P<0.05)$.

****Highly significant $(P<0.001)$. 


\section{Gingival health status:}

The autistic patients were affected by mild and severe gingivitis more than the control group as seen in Figure 1.

\section{Discussion}

Autism, autistic disorder, childhood autism, or infantile autism are different terms given to the same condition ${ }^{26}$. This study is the first attempt to systematically identify the problems of dental care for individuals who were suffered from autism in the Erbil, Iraq. The mean dmft of the autistic group was $11.57 \pm 11.41$ while that of the controls was $15.36 \pm 12.81$. The mean DMFT of the autistic group was $2.36 \pm 3.86$ and $2.89 \pm 3.78$ in the controls. This level of dental caries is considered low according to the WHO classification. ${ }^{27}$ These findings are in agreement with other studies which reported lower caries prevalence in autistic children. ${ }^{4,19,28}$ With advancing age, the values of decayed, missing and filled teeth increased. This finding was similar to the study that conducted by $\mathrm{JABER}^{5}$ in 2011. This increase may be due to the effects of time on the increased number of teeth susceptible to decay such as the second permanent molars, which erupt during adolescent period. ${ }^{29}$ Rajic and Dzingalasevic ${ }^{30}$ (1989) reported that a combined treatment, provided by a dental team and a pedopsychiatric team working together, resulted in a lowering prevalence of caries in autistic children group as compared to another group who did not receive any treatment. In present study non autistic group experienced more carious problem compared with the autistic group this may be due to more frequent snacking, which generates higher levels of dental caries among non autistic group and another reason missed or cancelled dental appointments in the non autistic group due to busy lifestyle or economical reasons. Addressing the prevalence of dental caries among non autistic children in Erbil, Iraq will require increased oral health promotion for parents and teachers both at the preschool stage and primary school age to enable them to implement effective preventive regimes for their children. Improving access to dental care and encouraging uptake of dental services should also form part of any health promotion strategy for autistic and non autistic children about reducing the frequency of sugary foods and drinks in the diet, use of fluoride toothpaste, and early attendance at the dentist or dental nurse for advice and care. The males in both groups showed higher mean values of

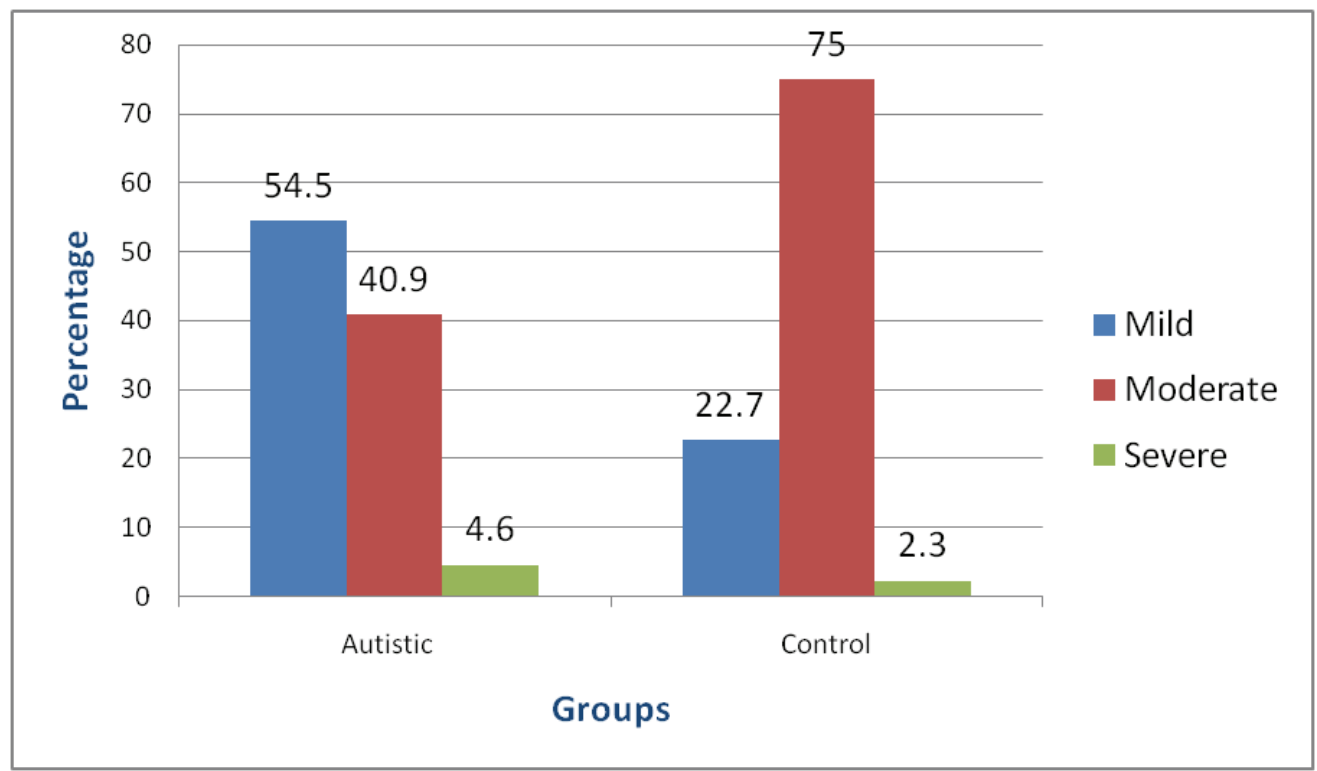

Figure 1: Severity of gingivitis in the two study groups. 
OHI-S than females with a significant difference $(P=0.042)$, this may be due to the studied group showed more males than females. In present study, almost all of the autistic children had fair oral hygiene and had gingivitis. These changes could be due to lack of the necessary manual dexterity of autistic children, which result in inadequate tooth brushing. It could also be related to irregular brushing techniques because of the difficulties the trainers and the parents encountered when they brushed the children's teeth. Another possible explanation for the presence of gingivitis might be the side effects of medications used to control the autism. ${ }^{9}$ In this study non autistic group also experienced fair oral hygiene and gingivitis this may be due to more frequent snacking, which generates higher levels of dental plaque and gingivitis among the non autistic group. Comprehensive dental treatment under general anesthesia may be required 30 percent of the time. ${ }^{31}$ When dental needs are great and attempts at behavior modification are unsuccessful, general anesthesia in the operating room creates a controlled environment where care is delivered efficiently and effectively.

\section{Conclusion}

Autistic children displayed lower dmft, DMFT scores compared to control group, fair oral hygiene level, and had gingivitis than did the unaffected control children and hence non autistic children need further consideration.

\section{Competing interests}

The authors declare that they have no competing interests.

\section{References}

1. Russel G, Rodger LR, Ukommune OC, Ford T. Prevalence of Parent-Reported ASD and ADHD in the UK: Findings from the Millennium Cohort Study. J Autism DevDisord 2014; 10:10803-13.

2. DeMattei R, Cuvo A, Maurizio S. Oral Assessment of Children with an Autism Spectrum Disorder. J Dent Hyg 2007; 81(3):1-11.

3. Amaral DG, Schumann CM, Nordahl CW. Neuroanatomy of autism. Trends Neurosci 2008; 31:137-45.
4. Orellana LM, Silvestre FJ, Sanchis SM, Mihi VM, Bautista D. Oral manifestations in a group of adults with autism spectrum disorder. Med Oral Patol Oral Cir Bucal 2012; 17(3):e415-9.

5. JABER MA. Dental caries experience, oral health status and treatment needs of dental patients with autism. J Appl Oral Sci2011; 19(3):212-7.

6. Geschwind DH. Autism: many genes, common pathways? Cell 2008; 135:391-5.

7. World Health Organization. Pervasive developmental disorders. In: International Statistical Classification of Diseases and Related Health Problems (ICD-10). Geneva: WHO; 2006.

8. Rogers SJ. What are infant siblings teaching us about autism in infancy? Autism Res 2009; 2:12537.

9. Rapinl, Tuchman RF. Autism: definition, neurobiology, screening, diagnosis. Pediatr Clin North Am 2008; 55:1129-46.

10. Ferrando-Lucas MT, Martos-Pérez J, Llorente-Comí M, Freire-Prudencio $S$, Ayuda-Pascual R, MartínezDíez-Jorge C, et al. The autistic spectrum. An epidemiological study and analysis of pos-sible subgroups. Rev Neurol2002; 34 Suppl1:S49-53.

11. Namal N, Vehit HE, Koksal S. Do autistic children have higher levels of caries? A crosssectional study in Turkish children. J Indian Soc Pedod Prev Dent 2007; 25:97-102.

12. Waldman HB, Perlman SP, Borg PA. Are dental hygienists prepared to meet the needs of patients with disabilities?. J Pract Hyg 2003; 12:22-4.

13. Waldman HB, Fenton SJ, Perlman SP. Preparing dental graduates to provide care to individuals with special needs. J Dent Educ 2005; 69(2): 249-54.

14. Newschaffer CJ, Croen LA, Daniels J, Giarelli E, Grether JK, Lewy SE, et al. The epidemiology of autism spectrum disorders. Annu Rev Public Health 2007; 28:235-58.

15. Fombonne E. Epidemiology of pervasive developmental disorders. Pediatr Res 2009; 65:591-8.

16. Rutter M. Incidence of autism spectrum disorders: changes over time and their meaning. Acta Paediatr 2005; 94:2-15.

17. Fahlvik-Planefeldt $C$, Herrstrom P. Dental care of autistic children within the nonspecialized Public Dental Service. Swed Dent J 2001; 25:113-8.

18. Shapira J, Mann J, Tamari I, Mester R, Knobler $\mathrm{H}$, Yoeli $\mathrm{Y}$, et al. Oral health status and dental needs of an autistic population of children and young adults. Spec Care Dentist1989; 9:3841.

19. Loo CY, Graham RM, Hughes CV. The caries experience and behavior of dental patients with autism spectrum disorder. J Am Dent Assoc 2008; 139:1518-24.

20. World Health Organization. Oral Health Survey. Basic Methods. $4^{\text {th }}$ ed. Geneva: Switzerland; 1997. 
21. Shah AF, Tangade $P$, Ravishankar TL, Tirth A, Pal S, Batra M. Dental Caries Status of Institutionalized Orphan Children from Jammu and Kashmir, India. Int J ClinPediatr Dent 2016; 9(4):364-71.

22. Peter S. Indices in dental epidemiology. Essentials of preventive and community dentistry. $2^{\text {nd }}$ ed. AryaMedi publishing house, New Delhi 2004, 127-240.

23. Oredugba FA, Akindayomi Y. Oral health status and treatment needs of children and young adults attending a day center for individuals with special health care needs. Biomed Chromatogr Oral Heath 2008; 8:30.

24. Sabir SM. Caries experience, periodontal health status and treatment needs among 6-18 years old type 1 diabetic patients 2010. M. Sc. Thesis (unpublished). Hawler Medical University, Collage of Dentistry; Iraq.

25. Sikarwar AS, Parolia A, Runai FA, Barua A. Relationship between Gingivitis and Autism in children: A Matched Case- control Study. British Microbiology Research Journal 2015; 7(4):174-79.

26. American Psychiatric Association. Pervasive developmental disorders. Diagnostic and statistical manual of mental disorders. Washington DC: American Psychiatric Association; 2000. P. 69-70.

27. Barmes DE. Indicators for oral health and their implications for developing countries. Int Dent $\mathrm{J}$ 1983; 33:60-6.

28. Murshid EZ. Oral health status, dental needs habits and behavioral attitude towards dental treatment of a group of autistic children in Riyadh, Saudi Arabia. Saudi Dent J 2005; 17:132-9.

29. National Institute of Dental and Craniofacial Research. Epidemiology and oral disease prevention program. Oral health of United State children, the national survey of dental caries in U.S. school children: 1986-1987. Bethesda: NIDCR; 1989. (NIH Publication No. 89-2247)

30. Rajic A, Dzingalasevic G. Autistic children and dental care. Acta Stomatol Croat 1989; 23:175-83.

31. Klein U, Nowak AJ. Autistic disorder: a review for the pediatric dentist. Pediatr Dent 1998; 20:312-7. 